\title{
Uma Reflexão de Professores sobre Demonstrações Relativas à Irracionalidade de $\sqrt{2}$
}

\author{
Teachers' Considerations on the Irrationality Proof of $\sqrt{2}$
}

\author{
Carmen Vieira Mathias * \\ ORCID iD 0000-0001-5667-159X \\ Luisa Rodríguez Doering** \\ ORCID iD 0000-0002-9678-7682 \\ Cydara Cavedon Ripoll ${ }^{* * *}$ \\ ORCID iD 0000-0002-7645-5322
}

\begin{abstract}
Resumo
Neste artigo, são apresentadas ponderações a respeito de uma reflexão em grupo sobre a análise dos erros cometidos em uma atividade proposta a professores que são alunos de um mestrado profissional em Matemática. A discussão realizada diz respeito a um conteúdo matemático que é ensinado na Educação Básica, bem como à reflexão dos sujeitos quanto às respostas apresentadas a uma atividade desenvolvida relacionada a esse conteúdo. De caráter qualitativo, este trabalho teve como instrumentos de coleta de dados a produção textual dos sujeitos, as observações realizadas pelas autoras e anotadas em um diário de campo, além de um questionário (online). Como aportes teóricos, utilizaram-se metodologias decorrentes da Análise de Erros, visando classificar os erros cometidos, para posterior discussão e reflexão em grupo. Os resultados indicam que os participantes perceberam como relevante a reflexão realizada, pois manifestaram reconhecer como fundamental que o professor leve em consideração os erros dos alunos em suas atividades de sala de aula. Constatou-se, também uma fragilidade com relação à argumentação dos participantes em Matemática, o que reitera, para as autoras deste estudo, a necessidade de o profissional manter-se em formação continuada.
\end{abstract}

Palavras-chave: Conhecimento Matemático para o Ensino. Análise de Erros. Reflexão em Grupo. Formação Continuada.

\footnotetext{
* Doutora em Matemática pela Universidade Federal do Rio Grande do Sul (UFRGS). Professora Associada da Universidade Federal de Santa Maria (UFSM), Santa Maria, Rio Grande do Sul, Brasil. Endereço para correspondência: Av. Roraima ${ }^{\circ} 1000$ - Prédio 13 - Departamento de Matemática, Cidade Universitária Camobi, Santa Maria, Rio Grande do Sul, Brasil, CEP: 97105-900. E-mail:carmen@ufsm.br.

** Doutora em Matemática por RUTGERS, New Jersey, EUA. Professora Associada da Universidade Federal do Rio Grande do Sul (UFRGS), Porto Alegre, Rio Grande do Sul, Brasil. Endereço para correspondência: Av. Bento Gonçalves, 9500 - Prédio 43-111 - Departamento de Matemática Pura e Aplicada, Bairro Agronomia, Porto Alegre, Rio Grande do Sul, Brasil, CEP: 91509-900. E-mail: ldoering @ mat.ufrgs.br.

*** Doutora em Matemática pelo Instituto de Matemática Pura e Aplicada (IMPA). Docente convidada do Programa de Pós-graduação em Ensino de Matemática da Universidade Federal do Rio Grande do Sul (UFRGS), Porto Alegre, Rio Grande do Sul, Brasil. Endereço para correspondência: Av. Bento Gonçalves, 9500 - Prédio 43111 - Departamento de Matemática Pura e Aplicada, Bairro Agronomia, Porto Alegre, Rio Grande do Sul, Brasil, CEP: 91509-900. E-mail: cydara@mat.ufrgs.br.
} 


\begin{abstract}
In this article, we offer considerations of a group reflection on the analysis of the errors committed in an activity proposed to teachers who are enrolled in a professional master's degree in mathematics. The discussion is related to a mathematical content that is taught in the basic school and to the manifestation of the subjects regarding their responses to a certain activity. In this research, of a qualitative character, the instruments of data collection were the subjects' textual production, the observations made by the authors and annotated in a field diary, as well as an online questionnaire. As theoretical contribution, we made use of methodologies that emerge from the Error Analysis theory, aiming to classify the errors committed for further discussion and reflection in the group. The results indicate that the participants perceived as relevant the carried-out reflection, because they expressed the recognition that it is fundamental for the teacher to take into account the students' mistakes in their classroom activities. The fragility of the argumentation in mathematics among these teachers was verified as well, and this reinforces the need for these professionals to embrace in-service teachers' education.
\end{abstract}

Keywords: Mathematical Knowledge. Error Analysis. Group Reflection. In-service Teachers- Education.

\title{
1 Introdução
}

As pesquisas de Carraro e Andrade (2011); Pivetta e Isaia (2014); Simão et al. (2009) focam na prática reflexiva coletiva em um espaço onde os professores compartilham suas experiências de sala de aula, de modo a motivá-los no sentido de reconstruir, desconstruir e [re]significar o seu papel enquanto educadores, transformando a prática pedagógica em aprendizagem docente reflexiva. Porém, Stylianides (2007) aponta que são poucas as pesquisas que tratam do conhecimento adquirido pelo professor ao refletir sobre algum conteúdo matemático.

Motivadas por esse trabalho, uma questão de investigação é aqui colocada: Quão necessário é o professor manter-se em formação continuada? A partir desse questionamento, o presente estudo tem como objetivo ponderar sobre uma reflexão realizada em grupo, por meio da análise dos erros cometidos em uma atividade proposta aos professores integrantes desse grupo, a respeito de um conteúdo matemático que é ensinado na Educação Básica.

No presente artigo, são relatados os resultados de cada etapa da atividade realizada, que objetivou investigar as seguintes questões: i) Como os sujeitos interagiram ao trabalhar em grupo e expor seus questionamentos sobre o conhecimento matemático relativo a um tema de sala de aula? ii) As reflexões realizadas pelo grupo contribuíram para a formação docente dos sujeitos?

Em um dos encontros com os sujeitos da pesquisa que antecedeu a atividade aqui relatada, discutiu-se o pensamento matemático na Educação Básica e foram explicitadas as 
ideias de Hanna ${ }^{1}$ (1995) sobre o tipo de demonstração que se espera ser levada para a sala de aula. Tais ideias revelaram-se uma novidade para os sujeitos. A seguir, foi proposta a eles a seguinte tarefa:

"A título de exercitar-se o pensamento matemático, solicita-se a demonstração da afirmação: Não existe um número racional cujo quadrado é igual a 2".

O objetivo dessa tarefa, em um primeiro momento, era de exercitar com os participantes da pesquisa o pensamento matemático na produção de uma demonstração, e, em um segundo momento, oportunizar uma reflexão coletiva sobre as resoluções apresentadas na primeira etapa, bem como escolher, dentre as diferentes demonstrações por eles produzidas, a(s) mais adequada(s) para determinado ano escolar, na perspectiva de Hanna.

Devido à surpresa das ministrantes quanto à variação do nível de precisão da linguagem utilizada e quanto aos erros cometidos, seguiu-se as orientações fornecidas por Cury (2013) e Torre (2007) na resolução da tarefa proposta (detalhada na seção 4), optando-se pela análise e categorização dos erros. Assim, para a segunda etapa da atividade, foi utilizada a Análise de Erros como metodologia de ensino, ponderando-se com os sujeitos as estratégias de resoluções utilizadas por eles, mais especificamente no que diz respeito aos erros e às dificuldades encontradas durante a resolução do problema proposto.

No que segue, apresentam-se, inicialmente, os aportes teóricos desta pesquisa, seguidos de sua metodologia e da descrição e análise da atividade proposta. Também se exibe uma avaliação dos sujeitos participantes com relação à atividade proposta.

\section{Aportes teóricos}

Levando em conta que neste trabalho utilizou-se a Análise de Erros como uma metodologia de ensino com alunos de um curso de formação continuada, proporcionando uma reflexão em grupo, de forma coletiva, a fim de analisar/ponderar sobre os erros cometidos por eles próprios, são apresentados alguns apontamentos sobre a análise de erros e a reflexão em grupo.

\footnotetext{
${ }^{1}$ Hanna é uma pesquisadora da Universidade de Toronto que defende o retorno das demonstrações à sala de aula, escolhendo-se aquelas que auxiliem a promover a compreensão: "O mais importante desafio aos educadores matemáticos, no que diz respeito a demonstrações, é abrilhantar o seu papel em sala de aula, encontrando caminhos efetivos de utilizá-la como veículo para promover o aprendizado e a compreensão da matemática" (HANNA, 1995).
} 


\subsection{Sobre a Análise de Erros como metodologia de ensino}

Ao procurar o significado da palavra erro na literatura existente, é possível encontrar, em pesquisas como Torre (2007), esse termo sendo interpretado como uma variável concomitante ao processo educativo, uma vez que, segundo o autor, "não há aprendizagem isenta de erros".

Em Cury (2010, p. 2), na resolução de uma questão, entende-se como erro

(...) o que não corresponde à produção esperada de um aluno (ou professor) que já deve ter tido contato com os conteúdos apresentados na referida questão ou com estratégias de resolução de problemas em Matemática.

Percebe-se, com isso, que o erro no ambiente escolar é, geralmente, conectado aos equívocos realizados pelo aluno. A crítica por não ter acertado incide sobre o aluno sempre que este não consegue chegar ao resultado conforme as expectativas do professor. Já em cursos de formação continuada de professores, nos quais os educadores encontram-se na qualidade de alunos, os erros cometidos por eles muitas vezes não são aceitos e são encarados de forma negativa. Porém, em Torre (2007), o erro é considerado como estímulo criativo, ou seja, como fonte de novas indagações, e já foi utilizado como fonte de inspiração em outras áreas, por exemplo, arte e literatura. Não se trata de transformar algo negativo em positivo, mas de valerse do equívoco como instrumento produtivo ou de progresso

Segundo Cury (2013), na Matemática, possíveis erros ou pontos questionáveis cometidos no processo de construção de um certo conhecimento, em geral, não são divulgados e explorados nem pelos professores, nem pela literatura. Assim, acredita-se que, ao trabalhar com as noções de obstáculo e erro durante a formação de professores de Matemática, tais sujeitos poderão perceber que o erro faz parte do processo e, a partir da reflexão sobre ele, serão capazes de sugerir estratégias na direção de melhor explorá-lo. Nesse sentido, em Cury (2013, p. 98) é apresentada a Análise de Erros como uma metodologia de ensino que proporciona

\footnotetext{
aos futuros docentes de matemática a oportunidade de olharem seus próprios erros para, com base em uma discussão sobre eles, retomarem os conteúdos nos quais apresentam dificuldades que, se não superadas, somente servirão para alimentar novas ocorrências de erros por parte de seus futuros alunos.
}

Em Cury (2013), é relatada uma experiência sobre a Análise de Erros com tópicos relativos a Pré-Cálculo no nível superior, e é exposta, de forma minuciosa, a metodologia que pode ser empregada em uma pesquisa de Análise de Erros. A metodologia por ela proposta é derivada da análise de conteúdo exibida em Bardin (1979), que é apresentada em três etapas: pré-análise, exploração do material e tratamento dos resultados. Na primeira fase, as respostas dos alunos são organizadas e formam os dados sobre os quais os pesquisadores 
realizam a análise. A seguir, as respostas são corrigidas, para uma primeira separação dos tipos de solução. A fase de exploração do material envolve o chamado processo de unitarização, o qual "consiste em reler o material para definir as unidades de análise (aqui chamadas de classes), que podem ser palavras, termos ou mesmo documentos em sua forma integral" (CURY, 2013, p. 66). Nessa etapa, também é feita uma classificação das respostas, quando o material é lido, mais uma vez, para a criação de categorias.

Já na fase de tratamento dos resultados, as categorias de respostas são descritas, em geral, com o apoio de exemplos retirados dos dados, podendo ser apresentadas por meio de quadros ou tabelas de distribuição de frequência.

Para o desenvolvimento de estratégias metodológicas/didáticas, Cury (2013) apresenta vários exemplos que podem ser trabalhados com professores de Matemática em cursos de formação inicial ou continuada. Nesse sentido, a autora destaca que a ideia é que o erro se constitua como um conhecimento, que é um saber que o aluno possui e que foi construído de alguma forma; assim, "é necessário elaborar intervenções didáticas que desestabilizem as certezas, levando o estudante a um questionamento das suas respostas" (CURY, 2013, p. 82).

A pesquisadora também ressalta que a estratégia a ser seguida não consiste em afirmar para o estudante que o modo como ele está fazendo é errado e que o correto é de outra forma. De fato, acredita-se que refletir sobre o erro e discuti-lo de forma conjunta pode ser uma estratégia eficaz, corroborando a visão de Torre (2007, p. 90):

O erro informa ao aluno que algo falhou na realização da tarefa ou na resolução de
problema e, por isso mesmo, o aluno deve mudar de enfoque ou estratégia no modo
de abordá-la. Leva-o a perguntar: "No que errei? Onde falhei? Como começar de
novo?". O erro induz a reflexão sobre o procedimento seguido. (...). Nesse sentido, o
aluno passa da postura receptiva própria de um modelo expositivo para um papel ativo
(...).

Sobre a análise de erros como metodologia de ensino, Cavassoto e Vialli (2011, p. 18) afirmam que

Do ponto de vista da didática de ensino da Matemática podemos aproveitar positivamente os erros cometidos pelos estudantes. Sentar com os alunos e discutir os caminhos que eles seguiram para solucionar uma determinada questão pode promover o diálogo entre educador e educando.

Quanto a dialogar/refletir sobre o erro, Kent (1978) apud Cury (2013) usou a tática de discutir com os estudantes as razões pelas quais estes foram cometidos, utilizando-os como um método de ensino e aprendizagem. Em Cury (1988) e Borasi (1987), têm-se pesquisas que focam em erros cometidos em demonstrações; já em Stylianies (2007, p. 290), é mencionado que existem poucos estudos desse tipo:

Poucas pesquisas, se é que existem, têm focado em como conceituar o significado da demonstração de uma forma que seja apropriada até para a matemática do ensino 
fundamental, ou em como uma tal conceituação poderia apoiar o estudo do papel dos professores no fomento da cultura da demonstração entre seus alunos. Em outras palavras, há uma escassez de pesquisas acerca das questões conceituais e instrucionais da demonstração e de suas conexões com a matemática na escola desde as séries elementares (Tradução das autoras).

No que segue, aborda-se a reflexão em grupo de professores e faz-se referência a obras que a apresentam como uma estratégia que pode ser utilizada em cursos de formação continuada.

\subsection{Sobre o processo de reflexão em grupo}

De acordo com Almeida (2006), o termo "reflexão" tem sido empregado frequentemente nas pesquisas sobre formação de professores. Também é possível encontrar esse termo em pesquisas realizadas em outras áreas do conhecimento, como em Silva, Araújo e Carrazoni (2016). Segundo Piveta e Isaia (2014, p. 114), o conceito de professor reflexivo

(...) foi sistematicamente referenciado por John Dewey, na década de 30. Conforme Dewey, o pensamento reflexivo envolve necessariamente um estado de imprecisão, hesitação, perplexidade e até mesmo dificuldade, o que origina o ato de pensar. A necessidade de solucionar algo consiste no fator orientador do pensamento reflexivo, da mesma maneira que "a natureza do problema a resolver determina o objetivo do pensamento e este objetivo orienta o processo do ato de pensar".

John Dewey também é citado por Silva, Araújo e Carrazoni (2016) por explicitar que um fator que merece atenção é o caráter individual do processo reflexivo. Porém, o artigo em questão expõe que o processo reflexivo pode ser catalisado pela participação em grupo.

Nessa mesma perspectiva, Raelin (2001) enfatiza que a relevância da reflexão em grupo decorre da possibilidade de dar e receber feedback, fazendo com que os indivíduos percebam as situações e os argumentos de forma diferente e aceitem que seus pares possam exercer efeito sobre eles.

No entanto, conforme Torre (2007, p. 91), "na formação de professores, seguem-se modelos pouco reflexivos e algumas vezes excessivamente teóricos e apoiados em receitas casuísticas". Além disso, ao pesquisar sobre o processo de reflexão em cursos de formação de matemática, são encontrados trabalhos que tratam da reflexão sobre a prática (ROSA; KATO, 2014; ZAKARIA; MAAT, 2010; POSTHUMA, 2012), nos quais é enfocada, essencialmente, a compreensão da reflexão sobre práticas de ensino. Em outras palavras, essas pesquisas incluem aspectos como plano de ensino, definição de metas, pontos fracos e fortes de sua prática docente e, principlamente, como lidar com os problemas dos alunos em sala aula. 


\section{Metodologia}

Nesta pesquisa, classificada como um estudo de caso quanto aos procedimentos técnicos, foi empregada a abordagem qualitativa, e, como guia para organizar e desenvolver os procedimentos metodológicos de ensino, foram utilizados os aportes teóricos da Análise de Erros.

Como fontes de informação da pesquisa, foram escolhidos os 12 professores que ingressaram no Mestrado Profissional em Matemática em Rede Nacional (PROFMAT) de uma instituição federal, no ano de 2016. Tais professores são licenciados em Matemática por diferentes Instituições de Ensino e atuam em diferentes regiões do estado em que se encontra essa universidade. Nesta pesquisa, passam a ser chamados de sujeitos e a ser identificados pelas primeiras 12 letras maiúsculas do alfabeto $(\mathrm{A}, \mathrm{B}, \mathrm{C}, \ldots, \mathrm{K}, \mathrm{L})$.

A escolha por esses sujeitos deve-se ao fato de estarem cursando a disciplina Tópicos de Matemática, ministrada pelas autoras deste estudo. Para a pesquisa e análise, foram obtidos "dados verbais" e "dados textuais" desses sujeitos.

Cabe ressaltar que uma das características do PROFMAT é buscar contemplar as necessidades do trabalho cotidiano dos professores no espaço da escola, especialmente no que diz respeito a uma formação profissional sólida em Matemática. Assim, o tipo de ensino/aprendizagem concebido pelo programa diz respeito, na sua maior parte, ao conhecimento de Matemática do professor. Destacam-se, aqui, as disciplinas denominadas básicas, a saber: Números e Funções Reais, Geometria, Aritmética e Matemática Discreta. Nessas disciplinas, poucos são os momentos efetivamente dedicados à Educação Básica. Porém, são oferecidas, também, disciplinas denominadas eletivas, cujo caráter pode contemplar, além do conhecimento matemático do conteúdo, o conhecimento matemático para o ensino.

O conhecimento matemático para o ensino, conforme Shulman (1986) é aquele "que vai além do conhecimento da disciplina em si para a dimensão do conhecimento da disciplina para ensinar”. Esse tipo de conhecimento foi contemplado na disciplina em questão, pois permitiu momentos de reflexão que conectaram a construção dos conhecimentos matemáticos à sala de aula. Assim, procurou-se observar como os sujeitos de pesquisa conduziriam as discussões propostas dentro de um espírito reflexivo e que priorizasse o conhecimento matemático para o ensino, sem deixar de enfatizar a necessidade do conhecimento matemático do professor.

Os espaços de interação social utilizados nesta pesquisa foram a sala de aula e o ambiente virtual de aprendizagem (AVA). Para o recorte aqui relatado, utilizaram-se dois 
encontros presenciais, de quatro horas cada. Como instrumentos de pesquisa, utilizouse a produção textual, advinda da tarefa solicitada e postada no AVA, as observações realizadas pelas autoras e anotadas em um diário de campo e um questionário (online) de encerramento/avaliação da atividade.

Após uma aula, na qual discutiu-se o que seria considerado como parte integrante do pensamento matemático na Educação Básica ${ }^{2}$, visto que esse não é universalmente definido, foi proposta aos sujeitos como tarefa individual, aquela já mencionada na introdução. Foi-lhes dado um prazo de cinco dias para a postagem das resoluções no AVA, para que as ministrantes pudessem, em tempo hábil, analisá-las e, a partir delas, planejar o próximo encontro com o grupo, dando continuidade à atividade.

A escolha da afirmação a ser demonstrada deve-se a três pontos: a) ao fato de que todos os sujeitos já haviam cursado a disciplina obrigatória Números e Funções, cuja bibliografia básica, Lima (2013, p. 55-56), apresenta uma demonstração de tal afirmação; b) ao fato de ser esta uma demonstração usual na maioria dos cursos de licenciatura; c) ao fato de $\operatorname{ser} \sqrt{2}$, em geral, o primeiro exemplo de número irracional dado na Educação Básica, de modo que o professor deve estar, na concepção das autoras, preparado para o eventual questionamento dos alunos “por que esse número é irracional?", podendo adaptar alguma dessas demonstrações ao nível do aluno.

Os sujeitos foram orientados a escrever por si mesmos a resolução, sem qualquer pesquisa em livros de graduação ou em livros didáticos, pois seria importante para o próximo encontro que tivessem surgido diferentes resoluções dessa tarefa (maiores detalhes sobre o objetivo da atividade e a continuidade dada a ela são relatados na seção 4). A expectativa das ministrantes era que efetivamente surgissem diferentes demonstrações, por exemplo, como as encontradas em Lima (2013) ou Ripoll, Ripoll e Silveira (2011). O planejamento original incluía uma discussão conjunta sobre a correção e o nível de detalhamento das argumentações utilizadas na resolução do problema, postadas no AVA, o que possibilitaria a promoção da compreensão, como sugere Hanna (1995), em estudantes de um específico nível de ensino.

Sendo assim, a atividade consistiu de quatro etapas:

1) a resolução da tarefa postada no AVA por parte de todos os sujeitos;

2) a análise dos erros das resoluções postadas, realizada pelas ministrantes antes do segundo encontro presencial com os sujeitos;

\footnotetext{
${ }^{2}$ Convencionou-se que o termo englobaria: conceituar, definir, testar para intuir, intuir, conjecturar, generalizar, particularizar e, principalmente, demonstrar.
} 
3) a reflexão com o grupo, no segundo encontro, sobre as resoluções apresentadas e os erros cometidos;

4) a ponderação, pelas ministrantes, das respostas ao questionário de avaliação respondido pelos sujeitos sobre a atividade, postados no AVA após o segundo encontro presencial.

\section{Descrição de cada etapa da atividade}

\subsection{Etapas 1 e 2: sobre as resoluções postadas no AVA e a análise dessas resoluções}

A partir da postagem das resoluções no AVA, as ministrantes puderam constatar, em uma primeira análise, que os sujeitos realmente fizeram um trabalho individual e sem consulta. Cabe salientar, também, que essa primeira análise surpreendeu as ministrantes, pois estas esperavam, como mencionado anteriormente, que a demonstração requerida fosse natural para os sujeitos. Assim, uma atividade que tinha, inicialmente, o objetivo de discutir quais das demonstrações que surgiram ajudariam a promover a compreensão e qual delas seria mais adequada a um $8^{\circ}$ ano do Ensino Fundamental ou a um $1^{\circ}$ ano do Ensino Médio, precisou ser reformulada, incluindo, no encontro presencial seguinte, um momento de reflexão sobre a correção dos argumentos utilizados.

A partir disso, a Análise de Erros foi adotada como metodologia de ensino. Para esse momento, foi previamente realizada, pelas ministrantes, uma análise dos erros cometidos pelos sujeitos, classificando-os de acordo com a complexidade dos argumentos utilizados na resolução do exercício, em ordem crescente. Após analisar todas as resoluções, os erros encontrados foram categorizados pelas ministrantes, obtendo-se cinco classes, descritas e exemplificadas na sequência.

\section{Classe I: Reflexão do sujeito sobre seu conhecimento matemático.}

Nessa classe, foram incluídos os erros provenientes da falta de reflexão do sujeito sobre o seu conhecimento matemático associado à resolução do exercício proposto. Esse tipo de comportamento é uma característica de alunos que se preocupam apenas em resolver exercícios, sem refletir sobre eles.

Nos 12 trabalhos apresentados, pôde-se observar:

i) Uma falta de reflexão do sujeito A (Figura 1), que não percebeu que a demonstração solicitada é equivalente à demonstração de que $\sqrt{2}$ não é um número racional, e usou esse fato como argumento na resolução do exercício. 


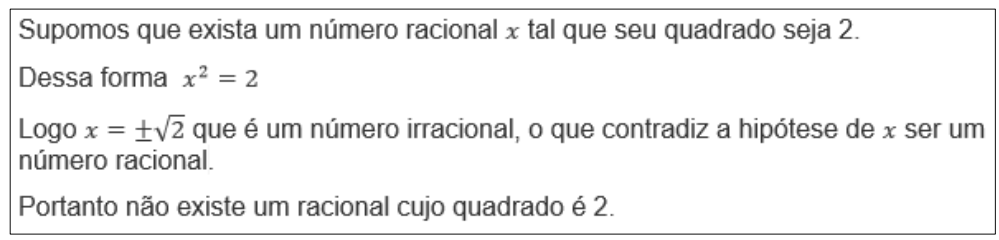

Figura 1 - Resposta do sujeito A

Fonte: Dados da pesquisa (2018).

Esse sujeito, que certamente foi exposto ao conhecimento matemático em questão, pois cursou a disciplina Números e Funções, não percebeu que é justamente a proposição a ser demonstrada uma das afirmações que motiva a ampliação do universo numérico dos racionais. Portanto, não era esperado que, para demonstrá-la, fossem utilizados números irracionais.

ii) A falta de reflexão do sujeito K, cuja argumentação recorreu a polinômios (Figura 2), surpreendeu as ministrantes, tendo em vista que ele tentou resolver um exercício que diz respeito a um conteúdo do Ensino Fundamental com argumentos de Ensino Médio, nem sempre estudados.

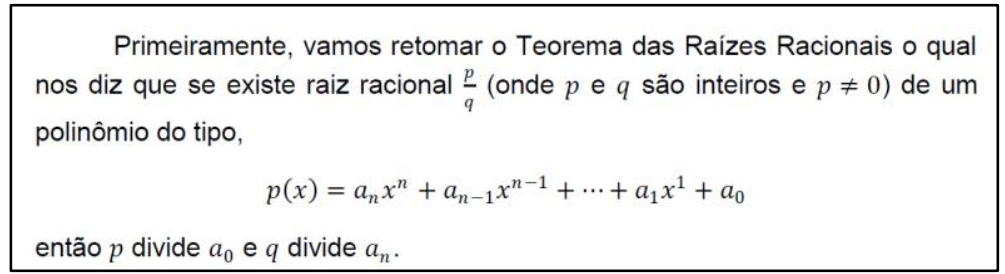

Figura 2 - Recorte da resposta do sujeito K Fonte: Dados da pesquisa (2018).

Notou-se, também, que o sujeito K mencionou o Teorema que lista os candidatos a raízes racionais para um polinômio com coeficientes inteiros, mas observou-se que falta a hipótese essencial: coeficientes inteiros. Portanto, o enunciado do teorema mencionado está incompleto. Além disso, cabe esclarecer que o sujeito, em sua argumentação, não testou nenhuma raiz, não utilizando, portanto, o teorema.

Cabe ressaltar que a falta de reflexão sobre o universo numérico dos sujeitos $\mathrm{A}$ e $\mathrm{K}$ não era esperada, visto que eles são professores de Educação Básica e atuantes nos anos em que esse resultado deveria ser abordado.

iii) O sujeito $\mathrm{B}$ apresentou erro em argumentação básica, envolvendo a definição de divisibilidade (Figura 3). A igualdade $p^{2}=2 q^{2}$ já garante que $p^{2}$ é um número par, independentemente de qualquer condição sobre os inteiros $p$ e $q$. Esse erro foi cometido duas vezes em sua resolução. 
A demonstração do sujeito $\mathrm{H}$ foi considerada incompleta por não estar claro se ele raciocinou por exaustão (todo número natural ou é par ou é ímpar) ou por contraposição, tendo, nesse caso, escrito demais ( $p$ ímpar implica $p^{2}$ ímpar, portanto, era desnecessário calcular o quadrado de um número par).

Nas demonstrações por absurdo apresentadas, sete sujeitos fizeram uso de frações irredutíveis e outros dois (I e J) não fizeram uso da afirmação "se o quadrado de um número é par (ou múltiplo de 2 ou divisível por 2), então tal número é par”, argumentando sobre o número de fatores primos que aparecem nas fatorações das quantidades envolvidas, como ilustra a Figura 6, o que, de fato, é possível.

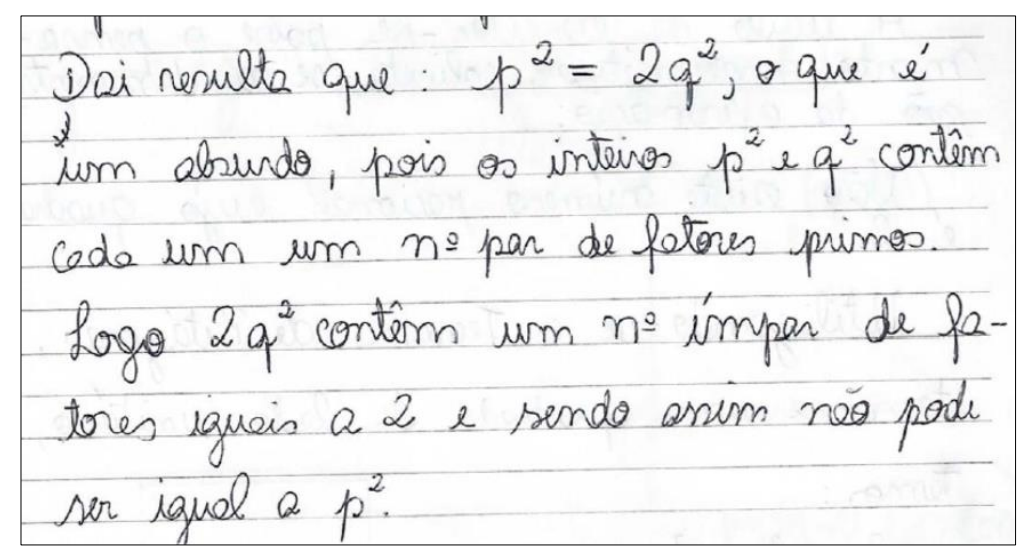

Figura 6 - Recorte da resposta do sujeito $\mathrm{J}$

Fonte: Dados da pesquisa (2018).

O erro, no caso do sujeito J, está no fato de ele não ter salientado que a fatoração em números primos é única, fato que sustenta a última afirmação. Por outro lado, sua argumentação é interessante, pois dispensa a hipótese extra e um tanto artificial de o numerador e o denominador da fração que representa o número racional serem tomados primos entre si. O sujeito usa, também, um argumento de contagem de primos que é bastante natural, porém não o detalha.

Esse mesmo sujeito também oferece uma demonstração alternativa ao recorrer a um argumento válido que não foi utilizado pelos demais; no entanto, não o demonstra: se um número primo divide um produto de inteiros, então divide um dos fatores (Figura 7).

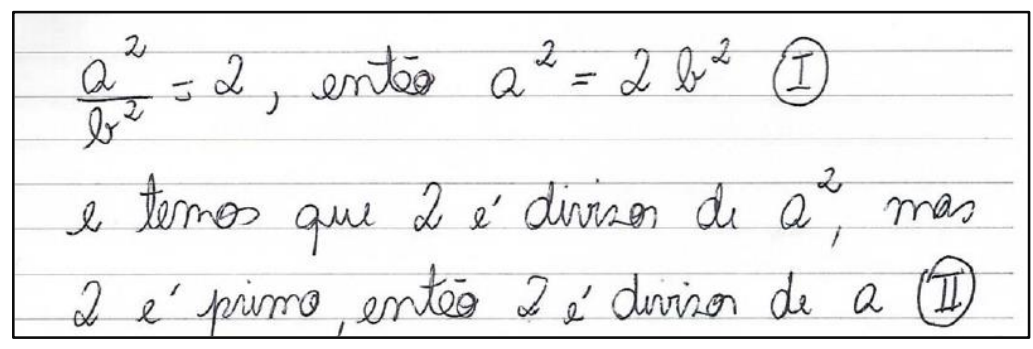

Figura 7 - Recorte da resposta do sujeito $\mathrm{J}$ Fonte: Dados da pesquisa (2018). 
Classe III: Familiaridade do sujeito com a escrita matemática

Nessa classe, foram incluídos os erros provenientes de uma falta de familiaridade com a escrita matemática, seja pelo uso de termos típicos da linguagem matemática como "tal que" ou "cujo" mal-empregados, seja pela inadequada ordenação das frases, ou pela confusão com a simbologia matemática. Além disso, foram incluídos casos de falta de clareza nas argumentações.

Neste exemplo, constata-se que existem alguns sujeitos que ainda explicitam uma não naturalidade com a simbologia matemática, como ilustra a Figura 8.

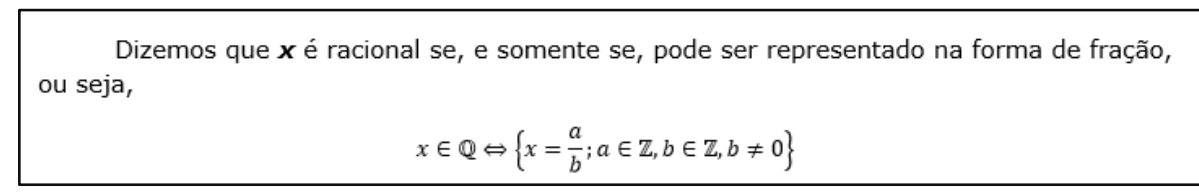

Figura 8 - Recorte da resposta do sujeito L Fonte: Dados da pesquisa (2018).

Nesse caso, o sujeito errou ao considerar o conjunto $\left\{x=\frac{a}{b} ; a \in \mathbb{Z}, b \in \mathbb{Z}, b \neq 0\right\}$ como uma proposição, como requer uma equivalência matemática.

Classe IV: Preocupação do sujeito com a transposição do resultado para a sala de aula

Levando em conta que o exercício apenas solicitava uma demonstração, foi considerado erro qualquer preocupação com a sala de aula. Três sujeitos (C, G e L) preocuparam-se com a sala de aula. Por exemplo, o sujeito G, mesmo considerando estar "falando para alunos que desconhecem os números irracionais", não conseguiu evitá-los em sua argumentação (Figura 9). Salienta-se, também, que a implicação $\left(\frac{a}{b}\right)^{2}=2 \rightarrow \frac{a}{b}=\sqrt{2}$ está errada, erro já classificado na Classe 1.

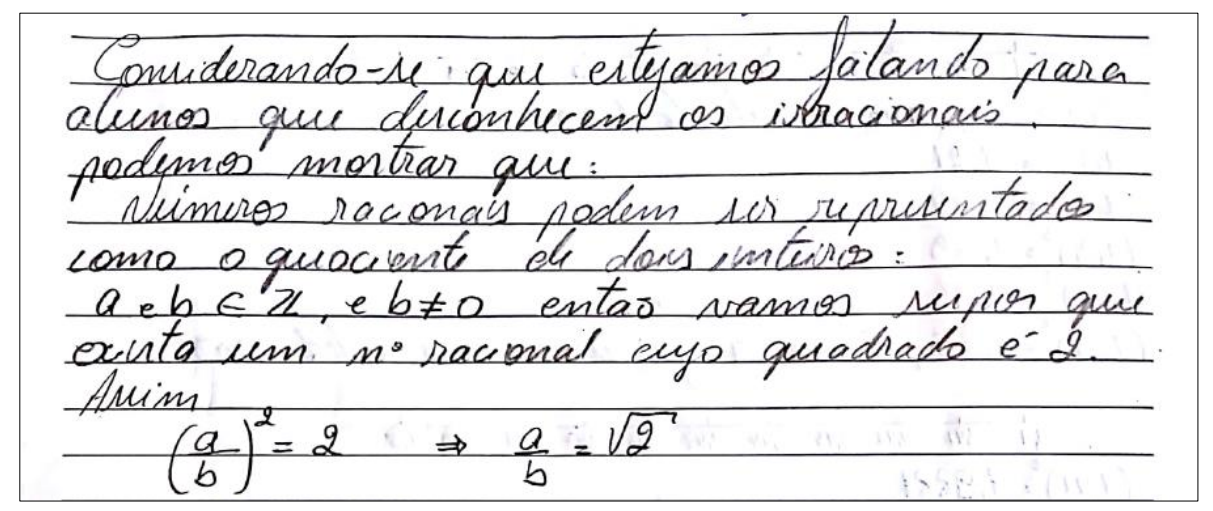

Figura 9 - Recorte da resposta do sujeito $G$ Fonte: Dados da pesquisa (2018). 
Finaliza-se essa seção ressaltando que nenhuma demonstração foi considerada totalmente correta e que alguns sujeitos cometeram erros em mais de uma classe. Na Tabela 1, apresenta-se um resumo dos erros cometidos por cada sujeito, e em qual classe isso ocorreu.

Tabela 1 - Distribuição dos erros segundo as classes

\begin{tabular}{|c|c|c|c|c|}
\hline Sujeito & Classe I & Classe II & Classe III & Classe IV \\
\hline $\mathrm{A}$ & $\bar{X}$ & $\bar{X}$ & & \\
\hline B & $X$ & $\mathrm{X}$ & $X$ & \\
\hline $\mathrm{C}$ & & $X$ & & $\mathrm{X}$ \\
\hline D & & $\mathrm{X}$ & & \\
\hline $\mathrm{E}$ & & $X$ & & \\
\hline $\mathrm{F}$ & & $X$ & & \\
\hline $\mathrm{G}$ & $X$ & $X$ & & $\mathrm{X}$ \\
\hline $\mathrm{H}$ & & $\mathrm{X}$ & & \\
\hline I & & $X$ & $\mathrm{X}$ & \\
\hline $\mathrm{J}$ & & $X$ & & \\
\hline K & $\mathrm{X}$ & $X$ & & \\
\hline $\mathrm{L}$ & & $X$ & $X$ & $X$ \\
\hline Total & 140 & & & \\
\hline
\end{tabular}

Cabe salientar, também, que o sujeito L foi o único que lembrou do que havia sido anunciado para o próximo encontro presencial (diferentes resoluções), procurando, sem êxito, segundo ele, por demonstrações variadas (Figura 10).

Também tive dificuldade com a tarefa proposta, em virtude de já ter clara esta demonstração em minha mente; tentei pensar de outras formas, sem sucesso. O máximo que cheguei foi adotar uma postura geométrica, imaginando um quadrado de lado 1 . Sua diagonal, pelo Teorema de Pitágoras, seria $\sqrt{2}$ e, em cima dessa diagonal construiríamos um quadrado de lado $\sqrt{2}$ e área 2. Mas isto me levava à redução ao absurdo de novo. Creio que fiquei condicionado, tal como queria evitar em meus alunos.

Figura 10 - Recorte da resposta do sujeito L Fonte: Dados da pesquisa (2018).

A variedade de erros cometidos pelos sujeitos, aqui relatados, levaram as ministrantes a alterar o planejamento do encontro seguinte, optando pela reflexão com o grupo sobre os erros cometidos, no lugar de simplesmente classificar as demonstrações por ordem crescente de complexidade e, a partir delas, analisar se alguma é ou pode ser adequada a um $8^{\circ}$ ano do Ensino Fundamental, bem como a um $1^{\circ}$ ano do Ensino Médio. Afinal, nenhuma das resoluções apresentadas constituiu uma demonstração.

Durante a reflexão de grupo, discutiu-se a adaptação da demonstração para a Educação Básica. Com o objetivo de ilustrar o que poderia ser considerado como uma demonstração da irracionalidade de "raiz de 2" para tal público, apresenta-se a seguir uma adaptação de Lima (2013). Será utilizado, como pré-requisito, que a fatoração em primos do quadrado de um número natural diferente de 0 e de 1 envolve um número par de fatores primos. Como enunciado adaptado, temos: Não existe um número racional cujo quadrado é igual a 2. Da mesma forma, 
como prova adaptada: Se existisse um número racional - digamos, $\frac{a}{b}$, sendo $a$, $b$ naturais e $b \neq 0$, cujo quadrado é igual a 2 , então $\left(\frac{a}{b}\right)^{2}=2$, ou ainda, $a^{2}=2 b^{2}$.

Se $a$ fosse igual a zero ou igual a 1, não seria possível tal igualdade; se $b$ fosse igual a 1 , então teríamos $a^{2}=2$, sendo $a$ um número natural, o que também não seria possível. Assim, $a$ e $b$ são diferentes de 0 e de 1 , portanto possuem uma fatoração em primos.

Pelo pré-requisito apontado anteriormente, $a^{2}$ e $b^{2}$ possuem ambos um número par de fatores em sua fatoração em primos; então, $2 b^{2}$ possui um número ímpar de fatores primos, o que impossibilita ${ }^{3}$ a igualdade $a^{2}=2 b^{2}$. Assim, concluímos que não existem $a, b$ naturais tais que $\left(\frac{a}{b}\right)^{2}=2$, ou seja, não existe número racional cujo quadrado é igual a 2 .

\title{
4.2 Etapa 3: sobre a reflexão com o grupo sobre os erros cometidos
}

Com a finalidade de promover a reflexão (sobre a atividade) com o grupo, as ministrantes propuseram, no segundo encontro presencial desta atividade, projetar as 12 resoluções, sem identificação do autor, para que o grupo as analisasse, uma a uma.

A ordem das projeções foi baseada no grau de complexidade envolvido nos argumentos apresentados na resolução. Naturalmente, um novo objetivo se fez presente nesse encontro: a discussão quanto à correção e à forma de se expressar em Matemática. Nesse momento, destacou-se a importância e a relevância de começar por analisar as resoluções produzidas pelo próprio grupo. Salientou-se que o objetivo da avaliação a ser realizada em conjunto era tão somente de conscientização e de reflexão, buscando retificar-se o erro, sem qualquer intenção negativa, conforme alega Torre (2007, p. 138):

\begin{abstract}
A aprendizagem e a formação foram descritas por nós em termos de mudanças. Enquanto essa não acontece, não há uma aprendizagem realmente significativa. É, portanto, a consciência do sujeito sobre os seus erros o que contribuirá para eliminálos. A correção do professor por si só não introduz mudanças no sujeito, enquanto esse não refletir sobre seus erros. Isso é o que quero dizer com o termo retificação.
\end{abstract}

Ainda segundo Torre (2007), a correção pode ser realizada pelo professor, pelo aluno ou pelos colegas. Neste caso, como o intuito foi conscientizar o sujeito do seu erro, tivemos como prioridade a autocorreção e a reflexão em conjunto, visto que dessa forma também se evolui com o auxílio de outras pessoas.

A primeira resolução projetada pelas ministrantes foi a do sujeito A (Figura 1). Apesar

\footnotetext{
${ }^{3}$ Cabe ressaltar que, no Ensino Fundamental, a unicidade da fatoração em primos de um número natural diferente de 0 e de 1 é, geralmente, considerada intuitiva.
} 
de a projeção não estar identificada, o autor do trabalho se acusou e comentou que fez a tarefa da forma "mais simples". Questionou-se o grupo se havia erros nessa resolução, e alguns responderam que tudo o que estava escrito estava "correto". Com tal afirmação, acredita-se que, no entendimento dos sujeitos, cada frase que compõe o argumento é verdadeira, mas o conjunto delas não constitui uma resolução correta. Ninguém comentou sobre a inadequabilidade do termo "mais simples", utilizado oralmente pelo sujeito autor da resolução projetada. Acreditase que, nesse primeiro momento, os sujeitos ainda estavam um pouco tímidos para expor críticas a seus pares.

Ainda na discussão dessa primeira resolução, o sujeito B comentou que, quando se escreve algo, escreve-se “para a gente, não para que os outros leiam”, evidenciando que não levou em consideração que sua resolução seria lida por outras pessoas, no caso, no mínimo, pelas ministrantes. Segundo Torre (2007, p. 91), “Um professor que já superou a fase inicial atua mais por rotina que por reflexão, quando deveria ser a reflexão a acompanhar suas tomadas de decisões (...)".

Com a projeção da segunda resolução (a do sujeito B), o grupo foi questionado sobre o que poderia ser observado na resposta do colega. Todos teceram algum comentário sobre a técnica de demonstração utilizada, isto é, a demonstração por absurdo.

Na sequência, foram projetadas, uma de cada vez, as resoluções dos sujeitos C, D e E, nessa ordem, cujos erros foram considerados pelas ministrantes semelhantes aos cometidos pelo sujeito B, e integrantes da classe II. Durante a discussão, um dos participantes indagou "até onde vai uma demonstração? O que se assume quando vai demonstrar-se algo?”, evidenciando que todas as demonstrações que lhes foram apresentadas, tanto em sua graduação como em seu mestrado, não foram suficientes para elucidar tais questões. De fato, Dewey (1959) afirma que o pensamento reflexivo tem como objetivo final concluir algo e que leva a indagar, pois " [...] examinar até que ponto uma coisa pode ser considerada garantia para acreditarmos em outra é, por conseguinte, o fator central de todo o ato de pensar reflexivo ou nitidamente intelectual" (DEWEY, 1959, p. 20).

Pôde-se perceber, no decorrer dessa discussão, uma empolgação por parte dos sujeitos, que efetivamente aproveitaram o espaço para refletir sobre o trabalho dos colegas e o seu próprio, atingindo-se um dos objetivos da reflexão em grupo, corroborando a afirmação de Raelin (2001) no que diz respeito à possibilidade de dar e receber feedback.

No momento em que foi projetada a resolução do sujeito E, ele antecipou-se nos comentários: "essa é a minha solução e eu cometi os mesmos erros dos colegas". 
Percebeu-se que essa reflexão possibilitou aos sujeitos reconhecerem que ainda existe falta de conhecimento e de cuidado com aquilo que é produzido por eles próprios. Isso ficou mais evidente ainda ao projetar-se a resolução do sujeito F e ele declarar: "já sei, não provei que o quadrado é par e meu português está bem ruim". Isso ratifica a afirmação de Lopes e Silva (2016, p. 297):

O aprendizado ocorre quando se permite que o indivíduo seja capaz de aprender, quando se oportuniza diferentes maneiras de usar uma mesma experiência, pois isso o leva a realizar diversas associações e combinações de ideias, de acordo com as circunstâncias a que lhe são apresentadas.

Essa fala indica que o momento de reflexão oportunizou ao sujeito F um olhar diferente sobre sua produção. $\mathrm{O}$ mesmo ocorreu com o sujeito $\mathrm{G}$, que percebeu a confusão de ideias apresentadas em sua resolução e, com o auxílio dos colegas, conseguiu compreender qual era, de fato, a intenção da atividade.

Embora as produções dos sujeitos H, I, J e K tenham sido tão comentadas quanto as anteriores, destaca-se aqui apenas o que parece mais relevante para o contexto deste estudo, isto é, o fato de que o aluno J utilizou-se de um apelo geométrico em sua resolução, algo que reforça a relevância do exercício proposto: aplicando o Teorema de Pitágoras a um quadrado de lado unitário, o enunciado do exercício traduz-se para a questão sobre a racionalidade do comprimento da diagonal do quadrado. Ao projetar-se a última resolução, a do sujeito L, ele afirmou não ter entendido a proposta da atividade, porém reconheceu que a exposição das produções dos colegas fez com que suas dúvidas fossem esclarecidas.

\subsection{Etapa 4: Relato das respostas dos sujeitos no questionário de avaliação da atividade}

Como uma das propostas da atividade relatada nesta seção é dar voz aos sujeitos, ouvindo suas reflexões acerca do saber matemático que têm, foi-lhes solicitado responderem, após o segundo encontro presencial, um questionário disponibilizado no AVA. Tal questionário serviu como mais uma fonte de informações para as ministrantes. Esse instrumento teve como objetivo avaliar o impacto da reflexão que a tarefa proposta teve sobre os sujeitos. Ele foi respondido por todos os 12 sujeitos que participaram da atividade. No que segue, é apresentada uma síntese das respostas obtidas. Ressalta-se que os questionários foram respondidos anonimamente, para que os sujeitos tivessem maior liberdade para fazê-lo.

Ao serem questionados se acreditam que a realização da tarefa foi proveitosa para a sua formação acadêmica, 11 responderam sim, enquanto apenas um respondeu talvez. Quando foram solicitados a justificar suas respostas, foi possível perceber, a partir dessas justificativas, 
que nem todos atingiram o objetivo da tarefa, mas houve, pelo menos, uma exceção, a saber, o sujeito que respondeu talvez. Para ele, a demonstração solicitada é simples e de conteúdo conhecido, então não desenvolveu muito o conhecimento, mas "se considerar a plenária, aí ajudou muito, a discussão enriqueceu muito o conhecimento a respeito de demonstrações" (Questionário do AVA, 2018).

Cabe ressaltar que esse sujeito não só se manteve coerente em sua justificativa como atendeu à expectativa das ministrantes de que a demonstração solicitada não deveria vir a constituir um problema para os sujeitos.

Ao serem questionados se acreditam que a atividade proposta foi proveitosa para a sua formação como professores, todos os sujeitos responderam que sim, sendo que dois deles ainda ressaltaram a importância da demonstração nesse processo, afirmando que "Sempre é importante relembrarmos algumas demonstrações de assuntos que podem e devem vir à tona quando estamos frente a alunos indagadores" (Questionário do AVA, 2018).

No que diz respeito, especificamente, à discussão realizada a partir das respostas projetadas, todos os sujeitos concordaram que ela foi proveitosa para a sua formação como professores. Um deles evidenciou que o momento oportunizou sua reflexão como professor ao afirmar que "Sempre que temos a oportunidade de refletir sobre nossa didática, está contribuindo para nossa formação como professor" (Questionário do AVA, 2018).

Outro sujeito ressaltou que a discussão oportunizou uma reflexão sobre a linguagem empregada, reconhecendo que diversas linguagens foram apresentadas, sendo umas mais simples, outras mais complexas. Ele também acrescentou que "Nós, professores, enquanto alunos, conseguimos observar qual o linguajar mais adequado para tratar o assunto em sala de aula nos diversos níveis” (Questionário do AVA, 2018).

No que concerne aos erros por eles cometidos ou pela imprecisão nos argumentos, dois sujeitos foram explícitos quanto a esta reflexão, e um deles reconheceu: "Nem sempre estamos passando informações completas aos nossos alunos, ou considerando conteúdos já estudados. A discussão fez com que percebesse que devemos ter mais cuidado com isso" (Questionário do AVA, 2018). Cabe salientar, na última resposta relatada, que o sujeito reconhece que, em uma demonstração, as argumentações que se revelam naturais nem sempre são as mesmas.

Todos os sujeitos questionados manifestaram que a reflexão oportunizada pela discussão foi importante para a sua prática docente, e dois ressaltaram a importância da troca com os colegas. Destes últimos, um deles inclusive declarou: "Pretendo aplicar sistemática parecida com meus colegas na escola onde leciono” (Questionário do AVA, 2018).

Ao serem questionados sobre como as discussões realizadas iriam contribuir (ou não) 
para a sua formação enquanto professores, uma resposta se destacou por evidenciar a reflexão do docente: "Foram importantes por permitirem uma reflexão sobre o quanto detalhes podem causar confusões ou interpretações errôneas na Matemática” (Questionário do AVA, 2018).

Quando convidados a registrarem outras observações sobre a atividade realizada, apenas quatro sujeitos se manifestaram. Destaca-se aquela que exaltou a discussão oportunizada: "Discussão altamente produtiva e enriquecedora pelo volume de ideias e orientações apresentadas" (Questionário do AVA, 2018).

A partir das respostas dadas ao questionário, acredita-se que os sujeitos conseguiram discutir suas próprias concepções de erro. Reitera-se que, nessa atividade, o objetivo inicial não foi o de realizar a reflexão a partir dos erros, nem ao menos dar voz aos sujeitos, seja na reflexão em grupo, seja no questionário. Porém, a mudança para essa prática mostrou o quanto a troca de experiência e as diferentes visões foram enriquecedoras a todos os envolvidos.

\section{Considerações finais}

Neste trabalho, relatou-se uma atividade realizada com professores da Educação Básica em um curso de formação continuada que iniciou com a tarefa: A título de exercitar-se o pensamento matemático, solicita-se a demonstração da afirmação: Não existe um número racional cujo quadrado é igual a 2.

A atividade foi planejada, inicialmente, com o objetivo de exercitar com os sujeitos o pensamento matemático por meio da produção de uma demonstração. Era um propósito da atividade, também, oportunizar uma reflexão coletiva sobre as resoluções apresentadas na primeira etapa, bem como escolher, dentre as diferentes demonstrações produzidas pelos sujeitos, aquela(s) que promovesse(m) a compreensão de estudantes de um $8^{\circ}$ ano do Ensino Fundamental ou de um $1^{\circ}$ ano do Ensino Médio, quanto ao tópico em questão.

No entanto, a atividade teve seu objetivo alterado após a análise, por parte das autoras, das 12 resoluções, passando-se a incluir, como objetivo, uma reflexão em grupo baseada na Análise de Erros. Essa atividade foi apoiada nas ideias de Cury (2013), que aborda a Análise de Erros como uma metodologia de ensino que oportuniza aos estudantes reconhecerem os seus próprios erros e que gera uma reflexão sobre o processo de ensinar e aprender.

Para os sujeitos da pesquisa, foi relevante e salutar a interação com seus pares, em uma postura reflexiva, que provocou uma avaliação de suas próprias concepções e oportunizou uma prática do pensamento matemático, pois permitiu uma retomada de lógica, de técnicas de demonstração, de conceitos matemáticos e de sua pertinência na escola. Além disso, o termo 
"salutar" deve-se ao fato de que, apesar das resoluções não serem identificadas no momento da projeção, os sujeitos sentiram-se à vontade para se identificarem para os colegas e escutarem os comentários, bem como em externarem suas próprias reflexões, advindas do momento de discussão. Na perspectiva das autoras, isso evidencia que a reflexão em grupo e a Análise de Erros foi encarada pelos sujeitos de forma receptiva.

Pelas respostas obtidas no questionário de avaliação da atividade, foi possível perceber que todos os sujeitos questionados consideraram a reflexão oportunizada pela discussão importante para a sua prática docente, e dois ressaltaram também a importância da troca com os colegas. Assim, a atividade realizada reiterou para as autoras o quanto a troca de experiência e as diferentes visões podem ser enriquecedoras a todos os envolvidos. Pode-se, também, constatar a fragilidade da argumentação em Matemática entre esses professores, o que reforça a necessidade desse profissional manter-se em formação continuada, envolvendo conteúdos matemáticos e argumentações, seja sobre o conhecimento matemático, seja sobre o conhecimento matemático para o ensino.

Espera-se, com a realização deste trabalho que descreve o processo de reflexão realizado durante uma atividade e reflete sobre os erros conceituais acerca do conteúdo a ser ensinado, ter contribuído com a formação continuada de professores e fomentado pesquisas nessa direção.

\section{Referências}

ALMEIDA, L. M. W. Modelagem Matemática: um Caminho para o Pensamento Reflexivo dos Futuros Professores de Matemática. Revista Contexto \& Educação, Ijuí, v. 21, n.76, p. 115-126, 2006.

BARDIN, L. Análise de conteúdo. Lisboa: Edições 70, 1979.

BORASI, R. Exploring mathematics through the analysis of Errors. For the Learning of Mathematics, Montreal. v. 7, n. 3, p. 2-8, nov. 1987.

CARRARO, P. R.; ANDRADE, A. S. O professor do ensino fundamental em grupos de reflexão. Rev. Mal-Estar Subj., Fortaleza, v. 11, n. 4, p. 1339-1378, dez. 2011.

CAVASOTTO, Marcelo; VIALI, Lorí. Dificuldades na aprendizagem de cálculo: o que os erros podem informar. Boletim GEPEM, nº 59, p. 15-33, jul-dez. 2011.

CURY, H. N. Análise de erros em demonstrações de Geometria Plana: Um estudo com alunos do terceiro grau. 1988. 186f. Dissertação (Mestrado em Educação) - Faculdade de Educação, Universidade Federal do Rio Grande do Sul, Porto Alegre, 1988.

CURY, H. N. Análise de Erros. In: ENCONTRO NACIONAL DE EDUCAÇÃO MATEMÁTICA, 10., 2010, Salvador. Anais... Salvador: SBEM, 2010. p. 1-11.

CURY, H. N. Análise de erros: o que podemos aprender com as respostas dos alunos. Belo Horizonte: Autêntica, 2013. 
DEWEY, J. Como pensamos. 3. ed. São Paulo: Editora Nacional, 1959.

HANNA, G. Challenges to the Importance of Proof. For the Learning of Mathematics, Montreal, v. 15 , n. 3, p. 42-49, nov. 1995.

LIMA, E. L. Números e funções reais. Rio de Janeiro: Sociedade Brasileira de Matemática, 2013.

LOPES, J. I.; SILVA, J. H. M. O Pensar Reflexivo Como Objetivo. Revista Opinião Filosófica, Porto Alegre, v. 7, n. 1, p. 286-302, 2016.

PIVETTA, H. M. F.; ISAIA, S. M. A. Grupo reflexivo de professores da educação superior: Estudo sobre seus movimentos construtivos. Rev. Port. de Educação, Braga, v.27, n.1, p.111-132, jun. 2014.

POSTHUMA, B. Mathematics teachers' reflective practice within the context of adapted lesson study. Pythagoras, [s.1.], v. 33, n. 3, nov. 2012. Disponível em :

https://pythagoras.org.za/index.php/pythagoras/article/view/140/219. Acesso em: 22 abr. 2018.

RAELIN, J. A. Public reflection as the basis of learning. Management Learning, Thousand Oaks, v. 32, n. 1, p. 12-30, 2001

RIPOLL, J. B.; RIPOLL, C. C.; SILVEIRA, J. F. P. Números Racionais, Reais e Complexos. 2. ed. Porto Alegre: Editora da UFRGS, 2011.

ROSA, C. C.; KATO, L. A. A Modelagem Matemática e o Exercício do Professor Reflexivo: a experiência de Elias. Perspectivas da Educação Matemática, Campo Grande, v. 7, n.14, p. 220-235, 2014.

SILVA, A. B.; ARAÚJO, G. D. E.; CARRAZZONI, M. D. O processo de reflexão no contexto da ação: a percepção de executivos e empreendedores. Revista Eletrônica de Estratégia \& Negócios, Florianópolis, v. 9, n. 3, p. 155 - 181, set./dez. 2016.

SIMÃO, A. M. V. et al. Formação de professores em contextos colaborativos; Um projecto de investigação em curso. Sísifo - Revista de Ciências da Educação, Americana, v. 8, p. 61-74, 2009.

SHULMAN, L. Those who understand: the knowledge growth in teaching. Educational Researcher, Washington, v. 15, n. 2, p. 4-14, feb. 1986.

STYLIANIDES, A. J. Proof and Proving in School Mathematics. Journal for Research in Mathematics Education, Reston, v. 38, n. 3, p. 289-321, 2007.

TORRE, S. de La. Aprender com os erros: o erro como estratégia de mudança. Porto Alegre: Artmed, 2007.

ZAKARIA, E.; MAAT, S. M. B. An exploration of mathematics teachers' reflection on their teaching practices. Asian Social Science, Ontario, v. 6, n. 5, p. 147-152, 2010.

Submetido em 17 de Julho de 2019 Aprovado em 03 de Fevereiro de 2020 